\title{
THE EFFECT OF ATMOSPHERIC PRESSURE ON FREQUENCY AND PATIENT'S SUBJECTIVE PERCEPTION OF EPILEPTIC SEIZURE SEVERITY
}

Larisa Kovačević, Mirjana Vidović, Leila Avdić, Dževdet Smajlović

(C) by Acta Medica Saliniana ISSN 0350-364X

Type of manuscript: Professional papers

Title:

THE EFFECT OF ATMOSPHERIC PRESSURE ON FREQUENCY AND PATIENT'S SUBJECTIVE PERCEPTION OF EPILEPTIC SEIZURE SEVERITY

Authors:

Larisa Kovačević, Mirjana Vidović, Leila Avdić, Dževdet Smajlović

DOI: $10.5457 / 480$

\section{Afiliations:}

Department of Neurology, University Clinical Centre Tuzla, Medical Faculty, University of Tuzla, 75000 Tuzla,

Bosnia and Herzegovina

Received: 19.10 .2018

Corresponding author:

Larisa Kovačević

larisa.kovacevic@ukctuzla.ba

Objective: The aim of this study was to determine the atmospheric pressure effect on the frequency of certain types of epileptic seizures as well as on patient's subjective perception of the seizure "severity".

Subjects and methods: The study was conducted prospectively, from April, 4th 2012. and it lasted for one year. Included were patients with epilepsy, without cognitive impairment or with mild cognitive impairment (a score of mini mental status MMS> 23), who regularly take antiepileptics. Daily personal epileptic seizure calendar of all subjects was monitored for twelve months, and atmospheric pressure value was monitored using biometeorological calendar. The calendar recorded the date, the time of seizure, with the assessment of the seizure "severity" (from 1 to 5), and based on autoanamnestic and heteroanamnestic data.

Results: Of 150 subjects included in the study, 74 (49.3\%) were male, while 76 (50.7\%) were female. There was no statistically significant difference in age between male and female subjects, with a probability of $\mathrm{p}=0.082(\mathrm{t}=-1.751)$. There were 58 patients with generalized tonic-clonic seizures, (total 58), 56 patients with simple focal seizures, and 36 with complex focal seizures. The seizure frequency in both male and female subjects did not depend on the atmospheric pressure value. However, the seizure frequency is statistically more frequent in days of changing in atmospheric pressure (either decrease or increase) in both men and women. Pearson correlation revealed only statistically significant $(\mathrm{p}<0.031)$ negative correlation of the seizure severity with the difference (change) in atmospheric pressure in male subjects, and where the correlation was extremely weak with the coefficient of correlation of $r=-0,201$. Association of seizure type with atmospheric pressure and its changes did not reach statistical significance.

Conclusion: These results certainly require further monitoring of associated biometerological parameters and their effects on seizure onset.

\section{INTRODUCTION}

Epilepsy is a paroxysmal cerebral dysrrhythmia defined by three important characteristics: the suddenness of the process, brain origin and the disorder of the rhythm of the electrical brain activity (1). Seizures (crises, ictus events, attacks) are common to all epilepsies. They include a variety of clinical manifestations or sudden episodes of disturbance of motor, sensibility, behaviour, perception, awareness or other psychic functions, autonomic and other regulations.

The classification of seizures and epilepsy syndrome takes the central place in modern epileptology, although the classification process itself is as old as the study of epilepsy. The international classification, based mainly on the clinical form of seizure and the electroencephalographic findings, was adopted in 1981 and has been further modified. In 1989, ILAE (International
League Against Epilepsy) adopted the International classification of epilepsies, epilepsy syndromes and disorders, which highlights the symptoms and signs that show the localization of initial cerebral dysfunction and its spread (2). In 2017, the ILAE released a new classification of seizure types, based upon the existing classification formulated in 1981. and its extension from 2010. (3).

Biometeorology is an interdisciplinary science that studies the interaction system between living organisms and the environment. The biometerological warning, bioforecast, contain a description of the meteorological situation and announces the arrival of those weather conditions which may adversely affect human health in the next days. The goal of bioprognosis is the organization of preventive measures for the protection of the vulnerable groups health (4). 
Variations in biometeorological factors have an influence on the overall balance of the human body, as well as to changes in the condition of patients, primarily those with chronic diseases. Le Blanc and Mills (1932) stated that one of the oldest and best known disease whose association with climatic factors is mentioned, is epilepsy (5). Fluctuation in some climatic factors, e.g. air pressure, might influence one or more of the above mentioned factors, and thus lead to seizure.

The purpose of this study was to determine the effect of atmospheric pressure on the specific seizure types frequency as well as on patient's subjective perception of the seizure "severity".

\section{SUBJECTS AND METHODS}

The study was conducted prospectively, from April, 4th 2012. and it lasted for one year. Included patients with epilepsy who were regularly admitted to the Epileptology ambulance Department of Neurology, University Clinical Centre Tuzla, as well as patients in Health Centres of Tuzla Canton. The study includes only patients without cognitive impairment or with mild cognitive impairment (a score of mini mental status MMS> 23), who regularly take antiepileptics (6). Excluded are all patients whose cause of seizure might be associated with a febrile condition or some other diseases.

Subjects were divided into three groups on the basis of seizure type: group one had generalized tonic-clonic seizures, group two had simple focal seizures, and group three had complex focal seizures. Considering that the research was carried out in the period before the extension of the Classification of the epileptic seizures was released in 2017, this study follows the Classification released by ILAE in 1989 (2).

Daily personal epileptic seizure calendar of all subjects was monitored for twelve months. The calendar recorded the date, the time of seizure, with the assessment of the seizure "severity" (from 1 to 5), and based on autoanamnestic and heteroanamnestic data. Assessment of the seizure severity was the patient subjective experience rated on the five-point scale, ranging from 1 (slight seizure) to 5 (the most severe seizure) and according to the modified VAS pain scale (7). Atmospheric pressure values are monitored using biometeorological calendar. Daily biometeorological data from the Hydrometeorological Institute of the Federation of Bosnia and Herzegovina were used (8).

Statistical data processing was performed using the IBM SPSS Statistics V21 software. From the descriptive statistical parameters, the absolute and the percentage values of the characteristic, the arithmetic mean with the intervals of reliability and the corresponding standard deviations were calculated. We used nonparametric statistical methods, a hi-squared test, while one-way analysis of variance (ANOVA) and Pearson's linear correlation coefficient were used as parametric statistical methods.

\section{RESULTS}

Of the 150 subjects included in the study, 74 (49.3\%) were male, while 76 (50.7\%) were female. The mean age of male subjects was $26.72( \pm 2.52)$, with an average deviation for 11.05 years, while the mean age of female subjects was $29.99( \pm 2.65)$ with a standard deviation of 11.81 years. There is no statistically significant difference in the age between male and female subjects, with a probability of $\mathrm{p}=0.082(\mathrm{t}=-1.751)$.

The subjects were divided into three groups on the basis of seizure type. In the group of patients with generalized tonic-clonic seizures (total 58), 30 (51.7\%) were males and $28(48.3 \%)$ were females $(p=0.793$, $X=0.069$ ). The second group consisted of 56 subjects with simple focal seizures, 29 or $51.8 \%$ were males and 27 or $48.2 \%$ were females ( $p=0.789, X=0.071$ ). The third group consisted of 36 subjects, 15 (41.7\%) males and $21(58.3 \%)$ females $(\mathrm{p}=0.317, \mathrm{X}=1.00)$ (Table 1 . Figure 1).

Table 1. Seizure type according to sex

\begin{tabular}{|c|c|c|c|c|c|c|c|}
\hline \multirow{3}{*}{ Seizure type } & \multicolumn{4}{|c|}{ Sex } & & & \\
\hline & \multicolumn{2}{|c|}{ Male } & \multicolumn{2}{|c|}{ Female } & & & \\
\hline & $\mathrm{n}$ & $\%$ & $\mathrm{~N}$ & $\%$ & Total (type) & $\mathrm{X} 2$ & $\mathrm{p}$ \\
\hline GTC & 30 & 51,7 & 28 & 48,3 & 58 & 0,069 & 0,793 \\
\hline Simple focal & 29 & 51,8 & 27 & 48,2 & 56 & 0,071 & 0,789 \\
\hline Complex focal & 15 & 41,7 & 21 & 58,3 & 36 & 1,000 & 0,317 \\
\hline Total (sex) & 74 & 49,3 & 76 & 50,7 & $n=150$ & & \\
\hline
\end{tabular}

$\mathrm{X}$-value of chi-squared test, $\mathrm{p}$ - probability of rejecting the null hypothesis, n-number of respondents 


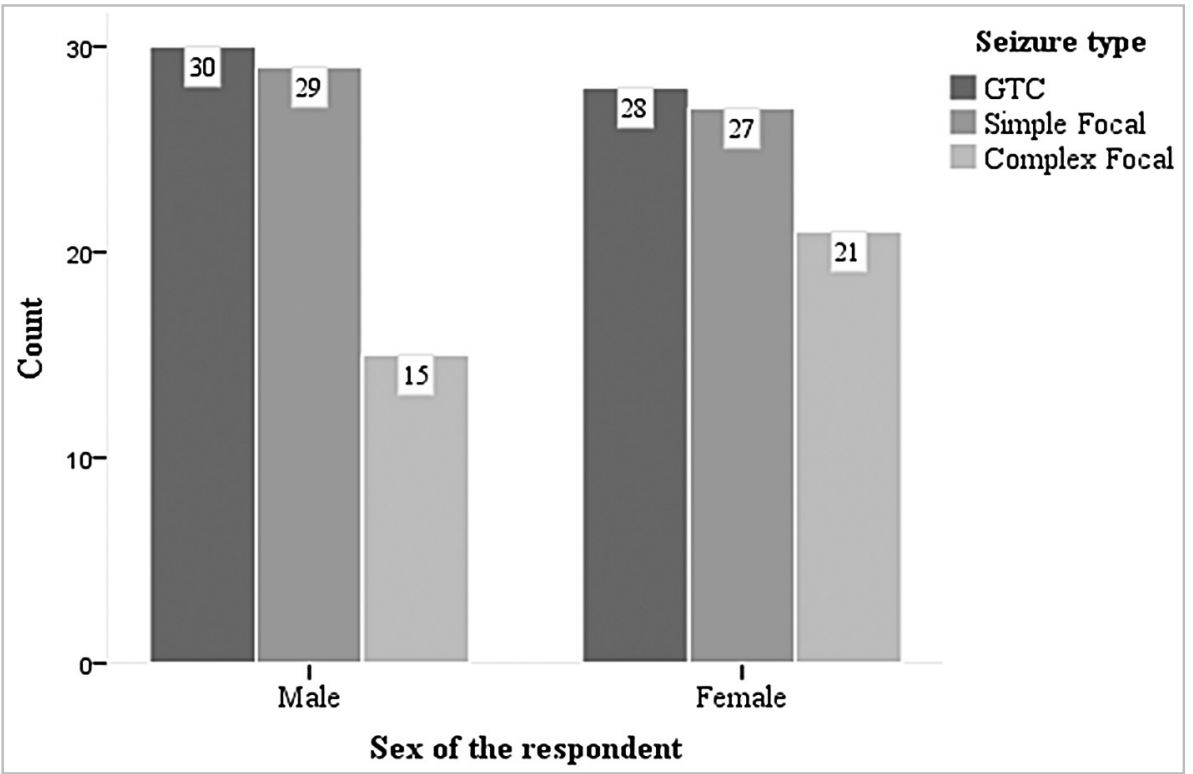

Figure 1. Seizure type according to sex

The seizure frequency in both male and female subjects did not depend on the atmospheric pressure value. (Table 2 and 3 ).

Table 2. The seizure frequency in male subjects according to atmospheric pressure value

\begin{tabular}{|l|c|c|cc|}
\hline \multicolumn{1}{|c|}{ Atmospheric pressure } & Seizure frequency & \% & X2 & $\mathbf{p}$ \\
\hline$\leq \mathbf{9 7 5} \mathbf{~ h P a}$ & 35 & 30,44 & & \\
\hline $\mathbf{9 7 6 - 9 8 0 ~} \mathbf{~ P a}$ & 44 & 38,26 & 1,270 & 0,530 \\
\hline$\geq \mathbf{9 8 1} \mathbf{h P a}$ & 36 & 31,30 & & \\
\hline Total & 115 & 100 & & \\
\hline
\end{tabular}

Table 3. The seizure frequency in female subjects according to atmospheric pressure value

\begin{tabular}{|l|c|c|cc|}
\hline \multicolumn{1}{|c|}{ Atmospheric pressure } & Seizure frequency & \% & X2 & $\mathbf{p}$ \\
\hline$\leq \mathbf{9 7 5} \mathbf{~ h P a}$ & 40 & 33,06 & & \\
\hline $\mathbf{9 7 6 - 9 8 0 ~} \mathbf{~ P P a}$ & 39 & 32,23 & 0,116 & 0,944 \\
\hline$\geq \mathbf{9 8 1} \mathbf{~ h P a}$ & 42 & 34,71 & & \\
\hline Total & 121 & 100 & & \\
\hline
\end{tabular}

The seizure frequency is more statistically significant in days of atmospheric pressure change (either decrease or increase) in both men and women (Table 4 and 5).

Table 4. Seizure frequency in male subjects according to the level of atmospheric pressure change

\begin{tabular}{|l|c|c|c|}
\hline \multicolumn{1}{|c|}{ Pressure change hPa } & Seizure frequency & \% & $\mathbf{X 2}$ \\
\hline $\begin{array}{l}\text { Decrease in } \\
\text { atmospheric pressure }\end{array}$ & 62 & 53,92 & \\
\hline $\begin{array}{l}\text { No change in } \\
\text { atmospheric pressure }\end{array}$ & 15 & 13,04 & $28,817 \quad 0,000$ \\
\hline $\begin{array}{l}\text { Increase in } \\
\text { atmospheric pressure }\end{array}$ & 38 & 33,04 & \\
\hline Total & 115 & 100 & \\
\hline
\end{tabular}


Table 5. Seizure frequency in female subjects according to the level of atmospheric pressure change

\begin{tabular}{|l|c|c|c|}
\hline \multicolumn{1}{|c|}{ Pressure change hPa } & Seizure frequency & $\mathbf{0}$ & $\mathbf{X 2}$ \\
\hline $\begin{array}{l}\text { Decrease in } \\
\text { atmospheric pressure }\end{array}$ & 58 & 47,93 & \\
\hline $\begin{array}{l}\text { No change in } \\
\text { atmospheric pressure }\end{array}$ & 14 & 11,57 & $26,793 \quad 0,000$ \\
\hline $\begin{array}{l}\text { Increase in } \\
\text { atmospheric pressure }\end{array}$ & 49 & 40,50 & \\
\hline Total & 121 & 100 & \\
\hline
\end{tabular}

Analysing the biometeorological variable - atmospheric pressure and the variable of experiencing the „severity“ of epileptic seizures, the results show that male subjects had „severe“ epileptic seizures in days of decrease in atmospheric pressure of $3.11 \mathrm{hPa}$ recorded. On days when they had a „slight" seizure, there was a decrease in atmospheric pressure by $0.67 \%$.

Female subjects had „severe“ seizures in days of the increase in atmospheric pressure on average $0.78 \mathrm{hPa}$ was recorded. In the days when they had an "slight" seizure an average decrease in atmospheric pressure of $0.29 \mathrm{hPa}$ was recorded.

In male group statistically significant and weak negative Pearson correlation of the seizure severity and the change in atmospheric pressure is observed $(r=-0,201 ; p<0.031)$. As shown on the diagram of scattering, figure 2 .

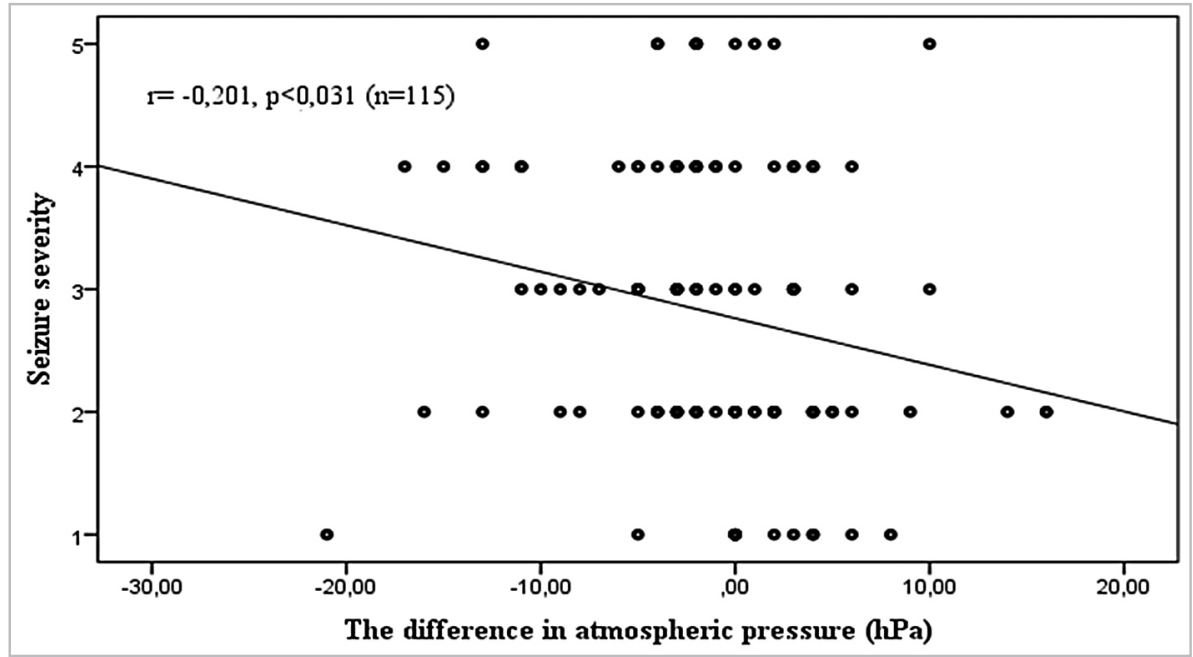

r- Pearson Correlation Coefficient, p- probability of rejecting the null hypothesis, n-number of siezures

Figure 2. Correlation of difference between atmospheric pressure and seizure severity in male subjects

One-way analysis of variance (ANOVA) revealed that the epileptic seizure type is associated with atmospheric pressure and its changes, both in male and female subjects.

Table 6 shows obtained atmospheric pressure parameters with respect to seizure types in male subjects.
Differences in average atmospheric pressure values between 3 seizure types in male subjects did not reach statistical significance, as shown by p-values of variance analysis greater than 0.05 , (Table 7 ).

\section{Table 6. Atmospheric pressure parameters with respect to seizure types in male subjects}

\begin{tabular}{|l|c|c|c|c|c|c|}
\hline \multirow{2}{*}{ Biometeorological factor } & \multicolumn{2}{|c|}{ GTC (n=34) } & \multicolumn{2}{c|}{ Simple focal (n=34) } & \multicolumn{2}{c|}{ Complex focal (n=47) } \\
\cline { 2 - 8 } & Mean & $\begin{array}{c}\text { Std. } \\
\text { Deviation }\end{array}$ & Mean & $\begin{array}{c}\text { Std. } \\
\text { Deviation }\end{array}$ & Mean & $\begin{array}{c}\text { Std. } \\
\text { Deviation }\end{array}$ \\
\hline Atmospheric pressure hPa & 977,85 & 5,21 & 978,94 & 5,78 & 977,96 & 5,91 \\
\hline Pressure difference hPa & $-1,74$ & 5,53 & $-1,24$ & 7,60 & $-1,36$ & 5,73 \\
\hline
\end{tabular}

Mean - Arithmetic Mean, n-seizure number 
Table 7. Analysis of dependence of seizure type on atmospheric pressure in male subjects

\begin{tabular}{|c|c|c|c|c|c|c|}
\hline & & $\begin{array}{l}\text { Sum of } \\
\text { Squares }\end{array}$ & df & $\begin{array}{l}\text { Mean } \\
\text { Square }\end{array}$ & $\mathbf{F}$ & $\mathbf{p}$ \\
\hline \multirow{3}{*}{ Atmospheric pressure hPa } & $\begin{array}{l}\text { Between } \\
\text { Groups }\end{array}$ & 25,503 & 2 & 12,752 & \multirow{3}{*}{0,396} & \multirow{3}{*}{0,674} \\
\hline & Within Groups & 3602,062 & 112 & 32,161 & & \\
\hline & Total & 3627,565 & 114 & & & \\
\hline \multirow{3}{*}{ Pressure difference hPa } & $\begin{array}{l}\text { Between } \\
\text { Groups }\end{array}$ & 4,675 & 2 & 2,337 & \multirow{3}{*}{0,059} & \multirow{3}{*}{0,943} \\
\hline & Within Groups & 4427,586 & 112 & 39,532 & & \\
\hline & Total & 4432,261 & 114 & & & \\
\hline
\end{tabular}

Sum of Squares - sum of squares deviations, Between Groups-deviation between groups,

Within Groups-deviations within the groups, Mean Square- average squares deviations,

df- degrees of freedom, F- Fisher test (ANOVA), p- probability of rejecting the null hypothesis

When it comes to analysing the correlation between atmospheric pressure and its changes with a particular seizure type in female subjects, one-way variance analysis did not reveal that average atmospheric pressure values were statistically significantly greater/ less in particular seizure type. The results obtained are shown in Tables 8 and 9.

Table 8. Atmospheric pressure parameters with respect to seizure types in female subjects

\begin{tabular}{|l|c|c|c|c|c|c|}
\hline \multirow{2}{*}{ Biometeorological factor } & \multicolumn{2}{|c|}{ GTC $\mathbf{( n = 3 0 )}$} & \multicolumn{2}{c|}{ Simple focal (n=38) } & \multicolumn{2}{c|}{ Complex focal (n=53) } \\
\cline { 2 - 7 } & Mean & $\begin{array}{c}\text { Std. } \\
\text { Deviation }\end{array}$ & Mean & $\begin{array}{c}\text { Std. } \\
\text { Deviation }\end{array}$ & Mean & $\begin{array}{c}\text { Std. } \\
\text { Deviation }\end{array}$ \\
\hline Atmospheric pressure hPa & 976,767 & 5,691 & 977,658 & 5,329 & 978,660 & 5,650 \\
\hline Pressure difference hPa & 0,100 & 7,919 & $-0,658$ & 3,815 & 0,396 & 6,837 \\
\hline
\end{tabular}

Mean - Arithmetic Mean, n-seizure number

Table 9. Analysis of dependence of seizure type on biometeorological factors in female subjects

\begin{tabular}{|c|c|c|c|c|c|c|}
\hline & & $\begin{array}{l}\text { Sum of } \\
\text { Squares }\end{array}$ & df & $\begin{array}{l}\text { Mean } \\
\text { Square }\end{array}$ & $\mathbf{F}$ & $\mathbf{p}$ \\
\hline \multirow{3}{*}{ Atmospheric pressure hPa } & $\begin{array}{l}\text { Between } \\
\text { Groups }\end{array}$ & 71,334 & 2 & 35,667 & \multirow{3}{*}{1,153} & \multirow{3}{*}{0,319} \\
\hline & Within Groups & 3649,806 & 118 & 30,931 & & \\
\hline & Total & 3721,140 & 120 & & & \\
\hline \multirow{3}{*}{ Pressure difference hPa } & $\begin{array}{l}\text { Between } \\
\text { Groups }\end{array}$ & 25,060 & 2 & 12,530 & \multirow{3}{*}{0,309} & \multirow{3}{*}{0,735} \\
\hline & Within Groups & 4787,932 & 118 & 40,576 & & \\
\hline & Total & 4812,992 & 120 & & & \\
\hline
\end{tabular}

Sum of Squares - sum of squares deviations, Between Groups-deviation between groups,

Within Groups-deviations within the groups, Mean Square- average squares deviations,

df- degrees of freedom, F- Fisher test (ANOVA), p- probability of rejecting the null hypothesis

\section{DISCUSSION}

Our results show that the value of atmospheric pressure did not affect the frequency of epileptic seizures in neither male nor female subjects. However, when atmospheric pressure change (either decrease or increase), statistically significant, more frequent epileptic seizures were recorded in both male and female subjects. Similar results were demonstrated in Doherty et al. study that showed that in patients with known epilepsy increased seizure frequency occurred with changes in barometric pressure, particularly over $5.5 \mathrm{mBar}$ range per day. The authors state that mechanisms of atmospheric pressure change on seizure susceptibility are speculative.
Patients with pseudoseizures or seizures of some other type did not show an increased frequency in the days of atmospheric pressure change (9).

One-way variance analysis of male and female subjects was applied to analyse the effects of atmospheric pressure change on specific seizure types (generalized, simple focal and complex focal) and the results did not show any statistical significance for any seizure. Similar results are also shown by other authors (10). In the study of Mott et al., the authors could not find evidence that atmospheric pressure changes significantly effect on frequency of any seizure type (focal, generalized or nonepileptic). However, they conclude that unstable 
weather conditions in spring, autumn and winter cause an increase in the frequency of seizures in almost half of the epileptic patients but only in $7 \%$ in summer. The increase in frequency of seizures in unstable weather conditions did not correspond in all patients with increase of changes in EEG. However, such results suggest an impact of these conditions on subclinical seizures (11).

In the study of Rakers et al., the authors report a linear negative correlation between atmospheric pressure and risk of seizure. The authors conclude that low air pressure and high relative humidity are associated with an increased risk for epileptic seizures, whereas high ambient temperatures seem to decrease seizure risk. They note that these results require further replication across different climate regions and cohorts before reliable clinical recommendations can be made (12). The results of our study show only a statistically significant negative correlation between subjective sensation of the severity of seizures and atmospheric pressure changes in male subjects. This significance is not evident in female subjects.

\section{CONCLUSION}

The seizure frequency in both male and female subjects did not depend on the atmospheric pressure value. The frequency was statistically higher in days when the atmospheric pressure change (increase or decrease) comparing to days when these changes did not occur. There were no significant correlation between seizure type and atmospheric pressure and its changes.

In male subjects there was a statistically significant, negative correlation between „severity“ of seizure and atmospheric pressure change, with the atmospheric pressure increase the sensation of seizure "severity" was decreased. There was no clear correlation between „severity“ of seizure and atmospheric pressure change in female subjects. These results certainly require further monitoring of associated biometherological parameters and their effects on seizure onset.

\section{REFERENCES}

1. Gibbs F, Gibbs E, Lenox G. Cerebral dysrythmias of epilepsy. Measures for their control. Arch Neurol Psychiatr 1938;39:298- 314.

2. Dreifuss FE, Henriksen O. Classification of epileptic seizures and epilepsies. Epilepsia 1989;30: 389 - 399.

3. Fisher et al. Instruction manual for the ILAE 2017 operational classification of seizure types. Epilepsia 2017;58(4):531-542. DOI: 10.1111/epi.13671. Epub 2017 Mar 8

4. Eastwood MR, Whitton JL. Biometeorology. Can Med Assoc 1985;133(2): 94.

5. Le Blanc, Mills CA Am. J. Epileptic seizures in relation to daily weather factors Am. J. Epidemiol 1932;16 (3):876879.

6. Rovner BW, Folstein MF. Mini-mental state exam in clinical practice. Hosp Pract.1987;22(1A): 99, 103, 106, 110.

7. Scott J, Huskisson EC. Graphic representation of pain. Pain. 1976;2(2):175-84

8. https://www.fhmzbih.gov.ba/latinica/KLIMA/godisnjaci. php

9. Doherty MJ 1 at all. Atmospheric pressure and seizure frequency in the epilepsy unit: preliminary observations. Epilepsia 2007;48(9):1764-1767. doi: 10.1111/j.15281167.2007.01111.x. Epub 2007 May 1

10. Doherty MJ at all. Do atmospheric pressure changes influence seizure occurrence in the epilepsy monitoring unit? Epilepsy Bewhav. 2009;16(1):80-1. doi:10.1016/j. yebeh.2009.06.023. Epub 2009 Jul 15

11. Motta E at all. Seizure frequency and bioelectric brain activity in epileptic patients in stable and unstable atmospheric pressure and temperature in different seasons of the year--a preliminary report. Neurol Neurochir Pol. 2011;45(6):561-6.

12. Rakers $F$ at all. Weather as a risk factor for epileptic seizures: A case-crossover study. Epilepsia2017; 58(7):1287-1295. DOI: 10.1111/epi.13776. Epub 2017 May 8.
Scan this QR code with your mobile device for instant access to the current Issue of Acta Medica Saliniana

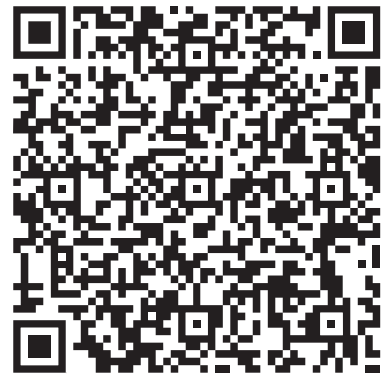

